\title{
DEMOGRAPHIC PROFILING OF RETAIL CONSUMERS IN ZIMBABWE
}

\author{
Sephath Mlambo \\ Lecturer. Department of Retail \& Logistics Management, Midlands State University. Zimbabwe.
}

\begin{abstract}
This paper explores the notion of consumer demographic profiling of Zimbabwe by using census and survey data from Zimbabwe's statistical agency ZIMSTAT. Certain trends emerged by examining secondary data mostly from 1962 when the first comprehensive census was conducted for Africans and non-Africans in Zimbabwe. A number of significant features come to light including age/sex composition, household size, population distribution and the changing role of women in the population and for decision makers within households. Conclusions and recommendations have been made concerning significant implications for all types of retailers of products and services.
\end{abstract}

KEYWORDS: Demographic profiling, retail consumers, Zimbabwe.

\section{INTRODUCTION}

Demography is the "scientific study of human populations, especially with reference to their size, structure, and distribution" (Collins, 2008). According to Freathy (2003) the number, age structure and location of individuals and households has considerable bearing on the size and location of target markets. Other significant demographic variables include population growth rates, age-sex composition, life expectancy, birth rates, fertility rates as well as socio-economic changes such as the participation of women in paid labour or levels of education across population groups. The study of demographics allows a retailer to form a demographic profile or picture of a consumer group in order to pinpoint opportunities and problems (Berman \& Evans, 2011); craft relevant strategies and decide on the products and services to offer or what promotion strategies to pursue.

Demographic factors affect people's retail shopping practices and decisions as well as retailer actions over a range of retail parameters (Berman \& Evans, 2011). A study of shopper attributes and behaviour in the retail sector in India recognized that "shoppers' age, gender, occupation, education, monthly household income, family size and distance travelled to store have significant association with retail format choice decisions" (Prasad \& Aryasri, 2011). The authors also asserted that demographic factors have important practical implications for food and grocery retailers, for creating better understanding of shopper behaviour, segmenting and targeting consumers and formulating of effective and competitive marketing strategies in the emerging Indian retail markets they studied. The end of the hyperinflationary environment in Zimbabwe followed by the introduction of the multi-currency regime in 2009 opened opportunities for expansion in the retail sector.

Vanhonacker, Lengard, Hersleth, \& Verbeke (2010) have also shown that there is a close relationship between age, household size and consumer preference for traditional foods among European consumers 
while Lee, Cho, Xu, \& Fairhurst (2010) explored the relationship between demographic factors and consumer traits on decisions to use retail checkout technologies. One of their findings was that younger and better educated consumers with high income showed a distinct preference for self-service checkouts. However, demographic factors alone do not fully explain retail practice or consumer choices and decisions. Thus, Prasad \& Aryasri (2011) asserted that "Traditional demographic variables cannot identify the complete characteristics of an evolutionary retail market because consumers in the same demographic group have very different psychographic make-up". Martínez \& Montaner (2008) observed that psychographic rather than the socio-demographic profiling of consumers better explains store brand proneness. In addition, Berman \& Evans (2011) also stated that for a comprehensive understanding of markets, retailers need a knowledge of the multitude of psychographic and social factors that influence behaviour. However, even these psychographic and social factors derive full meaning where they are considered jointly with their associated demographic variables. This study therefore, set out to uncover the range of demographics indicated here within the context of Zimbabwe.

Freathy (2003) defined retail as the sale of articles and services directly to final consumer. Such consumers buy products and services ranging from cars to apparel, to meals at restaurants and to movie tickets for their own personal, household and non-business uses (Anand, 2011). For this reason, understanding basic demographic parameters in any population is essential for the practice of retail.

Whereas demographic data provides vital data for retailers, however, such information may be dated as a full census is conducted once in ten years in most countries including Zimbabwe. Census data is also usually in broad categories and in summary form and so may not be useful in identifying niche retail markets for example. Population data is also often descriptive and would not offer subtle explanation of trends and distributions. For this reason, the quantitative approach adopted in this study carries an inherent limitation. Kotler \& Keller (2006) also cautioned that while demographic trends can be highly reliable in the short to intermediate run they are less reliable in the longer term.

Kotler \& Keller (2006) pointed out that, while growth in the size of the overall population is important, so also is the identification of special groups which they referred to as SSWD [single, separated, widowed, divorced] and other non-traditional households that have special needs for furniture and furnishings, appliances and food packages for example. These groups may also place special emphasis on convenience in both time and place. In a developing country such as Zimbabwe, the balance of these forces is in a state of flux.

Market segmentation is a strategic necessity for retailers. However, there are several approaches to segmentation basing on geographic, psychographic or demographic parameters. In either case, knowledge of population characteristics is important. Demographic segmentation may be conducted on the basis of age or life-cycle, gender income or generations or cohorts based on some profound influences or experiences in the times a segment of the total population grew up. In the case of the US for example, Kotler \& Keller (2006) described the special consumption styles and expenditure patterns of such groups as baby boomers [born in the years 1946-64], Generation X [1957-77], Generation Y [1978-94] and Millenials [1995-2002]. Thus, based on an understanding of a population group and its history, it may be possible to demarcate population segments in accordance with Zimbabwe's socio-economic circumstances in order to understand aspects of retail practice directed towards those demographic segments. Psychographic segmentation, which this study does not cover, would rely on psychological/personality traits, lifestyles and values of population groups.

Berman \& Evans (2010) have identified some significant implications of consumer demographics to demonstrate the importance of understanding consumer profiles:

- On gender, they observed that working women "tend to be more self-confident and individualistic; more concerned with convenience; more interested in sharing household tasks... more knowledgeable and demanding as consumers...more involved with self-improvement and education, more appearance-conscious, and more indifferent to small price differences among retailers". In addition, these tendencies may further influence men's and women's roles. 
- Consumer sophistication and confidence grow as shoppers become more knowledgeable and cosmopolitan; when they acquire heightened awareness of new trends in tastes and styles. Confident shoppers may experiment more; they become smarter and they read newspapers and other promotional materials. Some may even embrace online shopping for example.

In response to such consumer traits, retailers on their part may respond by adding branches to cut on travel time; open longer hours; add on-floor sales personnel or reduce check out time.

For all retailers, the total population size as well as the rate of population growth, its composition and distribution represent crude measures of retail market size. These variables are necessary in the assessment of retail competition or measuring trade area potential e.g. in Reilly's Law of Retail Gravitation. Such knowledge enables companies to evaluate the potential of market segments.

Berman \& Evans (2011) indicated that national demographic data provides only a broad overview. In reality there are important variations from one area to another: most retailers are local or operate within a region so relevant data needs to be compiled at those levels so that, for a given business and location, the characteristics of the target market can be better understood. This paper however was limited to a preliminary depiction of the demography of Zimbabwe with an emphasis on those variables which have significance for retailers from the available published demographic data.

Levy et al. (2012) have also identified the following additional approaches to segmenting retail markets:

- Geographic segmentation is anchored on where customers live; and then determining the number of potential customers in the area.

- Geo-demographic segmentation is founded on combining demographic and geographic characteristics to select locations and tailor assortments.

- Lifestyle [psychographics] segmentation relies on how people live, how they spend their money or time; the activities they pursue as well as their attitude or opinions about the world.

Because this study focused on demographics, the approaches listed above are covered only in passing and indirectly.

For any retailer, the household is an important consumption unit because a number of significant purchase decisions are made at the household level. It is, however, important to distinguish the family from a household. Berman \& Evans (2011) defined a family as a group of two or more people who are related by blood, marriage or adoption while a household is defined as a person or persons who occupy a housing unit whether they are related or not. In the compilation of population data in Zimbabwe, ZIMSTAT (2013) defined the household in a similar way. For the US, Berman \& Evans, (2011) quoted average household sizes at 2.7. The number, composition and size of households influence shopping patterns or frequency, types and quantities of goods or services required to satisfy the needs of household members individually or as a unit or the allocation of income to expenditure lines. Consumption would also vary depending on age, or sex composition of the household unit. Prasad \& Aryasri (2011), for example, highlighted the significance of household size and observed that larger household sizes having larger consumption levels appear to prefer supermarkets and hypermarkets for purchase of products in bulk where they might benefit from promotional offers.

\section{METHODOLOGY}

The objective of this research paper was to identify and describe the range of demographic factors pertinent to retailers in Zimbabwe and to relate these to retailing practice and theory. Demographic data for this paper was derived from Zimbabwe census and demographic survey reports. The study was therefore of a positivist nature using secondary data from public records. Such a study is, as Saunders, Lewis, \& Thornhill (2012) said, concerned with facts not impressions: research of this nature is therefore, on the face of it, "value-free". Census data involves phenomena which are measureable and objective using established 
procedures and methodologies and focussing on hard data rather than opinions and therefore, seeking regularities in the data (Easterby-Smith, Thorpe \& Jackson, 2008). Facts and values can therefore be clearly separated. Nevertheless, like all secondary data, such data may not accurately converge with the purpose of any particular subsequent research project. Yin (2009) referred to the use of census type data as archival analysis which he said is suitable for "what", "who" or "where" questions. Such approaches are advantageous when the research goal is to describe the incidence or prevalence of a phenomenon or when it is predictive of certain outcomes.

This study depended on the available census data as well as additional reports and surveys on aspects on the country's demography. Census data in Zimbabwe is collected every ten years by the Zimbabwe National Statistical Agency (ZIMSTAT) previously called Central Statistical Office (CSO). In between censuses, inter-censal demographic surveys are carried out based on defined sampling procedures. The 1982 census was the first post-independence census which enumerated both Africans and non-Africans at the same time. Income data, though desirable for a study of this nature was not readily available. This is understandable in the light of years of hyperinflation up to February 2009 when Zimbabwe dropped its currency and embraced the US dollar and South African Rand as its principal currencies of exchange. For years, ZIMSTAT has used the wealth index which combines data such as household assets, housing quality and fuel type in one composite index. The index was developed and tested in a large number of countries with the help of UN agencies and was found to be consistent with expenditure and income measures of poverty (CSO, 2010). The findings which follow also incorporate this element by way of reference to income quintiles.

\section{RESULTS AND DISCUSSION}

As stated earlier, the main source of demographic data for this study was census data which in Zimbabwe is generated by the Zimbabwe National Statistical Agency (ZIMSTAT) previously called the Central Statistical Office (CSO). By definition, census data is comprehensive but it is also broad and general in its nature. A second source was in the form of surveys conducted between censuses. In general, the purpose of such surveys was "to provide current information for policymakers, planners, researchers and programme managers" (ZIMSTAT, 2012). The 2002 National census report also recorded that detailed data had been put at the disposal of users to "assist in policy making, planning, administration, research, etc." (CSO, 2004). Clearly therefore, such data is relevant to this study of demographic profiling of retail consumers in Zimbabwe.

The first census enumeration of the African population who constitute the majority in Zimbabwe was undertaken in 1962 (just over 50 years ago). Since then, a census has been held after every ten years: the last one having been conducted in 2012 with the results published from 2013.

It is estimated that the population of Zimbabwe stood at just over 700000 in 1901; then it doubled in the 30 years up to 1931; subsequently the next doubling took just 20 years with growth rates at $2.31 \%$ in 1911 which then rose to a peak of $3.53 \%$ by 1951 (ZIMSTAT, 2013). By the time of the first post-independence census in 1982, the growth rate had fallen to $2 \%$ with the census report estimating that the 1982 population of 7.5 million would double itself by the year 2005 (CSO, 1985). However, by 2012 the population growth rate had declined further to $1.1 \%$ (ZIMSTAT, 2013) resulting in a much smaller population of just over 13 million not the 15 million predicted earlier. This underlines the fact that prediction and projections should be regarded with caution during any planning process whether for retail or in some other industry sector.

One notable finding of the 1997 inter-censal demographic survey was an increase in proportion of women being widowed before reaching the age of fifty years. This finding was attributed to the possible impact of HIV/AIDS: a condition also accompanied by declining life expectancy and higher dependency ratios. Another consequence was the growth in the number female-headed households together with a drop in household disposable incomes.

Most people live in households and the household is the basic social and economic unit of society. In the census and survey data, the head of the household was taken to be the person responsible for the day-to-day running of the household and considered as such by members of the household. Such a person may play a 
crucial role in the household's buying decisions being, most probably, the breadwinner in the household. It matters very much for retailers to be able to identify such individuals and customise product/service offerings accordingly. In 1997 the number of households was 2.51 million representing a $16 \%$ increase in five years: a much higher rate of increase compared to the $2.5 \%$ population growth rate of the time. The total number of households has continued to increase since then.

The 2002 census reflected a more modest increase to 2.6 million private households with an average size of 4 persons in each. Urban households were slightly smaller compared to the national average or to rural households for that matter. The largest proportion of households was $16 \%$ in the 3-4 persons category. In addition $82 \%$ of households had at most 6 persons.

In 2005 about $66 \%$ of households were headed by males. The balance had tilted somewhat in favour of females by 2006 as shown below:

\section{Household Headship}

\begin{tabular}{|l|l|l|l|}
\hline & Urban & Rural & Total \\
\hline Male & 71 & 57 & 62 \\
\hline Female & 29 & 43 & 38 \\
\hline
\end{tabular}

Based on CSO (2007)

By 2011, 45\% of households were headed by females up from 38\% in 2006 with almost all the increase coming from urban areas (ZIMSTAT, 2012). It may be that this demographic shift might last for some time into the future with consequential impacts on consumer spending decisions.

Zimbabwe's population is relatively youthful with nearly $41 \%$ being below 15 years and only about $4 \%$ aged 65 and above according to the 2002 census. Average fertility was about 3.6 children per woman and this seemed to vary with levels of education for the mother. In general, fertility rates have declined in most countries in line with literacy levels, economic development in general and women's participation in the economy in particular (CSO, 2004).

An important demographic feature in most developing countries such as Zimbabwe is the rate of urbanisation fuelled by both natural population growth and rural-urban migration. For Zimbabwe, urban dwellers are defined as those residing in compact settlements with a population of 2500 inhabitants or more. Out of a total population of just over 13 million in 2012, about 33\% were urban dwellers: Harare having $47 \%$ of the urban inhabitants. In addition, the two largest cities (Harare and Bulawayo) had the fastest rate of natural population increase as well as the highest rate of inwards migration (ZIMSTAT, 2013). The Africa Report (Africa in 2012, 2012) estimated that $38 \%$ of Zimbabweans lived in urban centers suggesting continuing urbanisation as is the pattern worldwide. Clearly the major towns and cities will be the focus for retail growth and development.

The 2005/6 Zimbabwe Demographic and Health Survey (CSO, 2007) recorded that life expectancy stood at 61 years in 1992. However, this had declined to 45 by 2002. Between the same dates, the proportion aged below 15 fell from 45 to $41 \%$ while those above 65 registered a marginal increase from $3.3 \%$ to $4 \%$. Life expectancy however, appears to be on the rise with the 2012 census reporting it at 58 years at birth. (ZIMSTAT, 2013). Crude birth-rate fell from $34.5 \%$ to $30.3 \%$ while the crude death rate recorded a sharp movement from $9.5 \%$ to $17.2 \%$. In many developed countries life expectancy is much higher e.g. 83 years in Canada for females and 76 for males. However, neighbouring South Africa had average life expectancy of 49 (Berman \& Evans, 2011).

From a retailing perspective, the educational level of household members is one of the most important characteristics because the level of education has a bearing on many consumption choices (ZIMSTAT, 
2012). The median age of educational attainment was 6.7 years for males and 6.5 for females. Unsurprisingly, the median is highest in Harare and Bulawayo, the largest cities in the country.

Some $41 \%$ of Zimbabwe's population was under the age of 15 years (ZIMSTAT, 2013). This group forms an important emerging target sector for any retailer for products such as fast foods, clothing and everyday food and grocery products or for banking or Internet services. Zimbabwe has one of the highest levels of literacy on the African continent at about $97 \%$ for those above 15 years of age (ZIMSTAT, 2014). This compares favourably with $99 \%$ for Japan and the United States and $86 \%$ for South Africa, perhaps the biggest economy on the African continent. Literacy is an important demographic variable which influences the types of products or services bought or the promotion strategies available for retailers or knowledge of alternatives. However, there are different definitions of literacy. For census purposes, ZIMSTAT (2013) used three years of schooling as the benchmark. However, for its inter-censal demographic surveys, the organisation applied a functional reading test on people who had not undergone secondary education. On either basis, literacy levels in the high levels have been recorded (ZIMSTAT, 2013).

Younger people are more likely to have had an education and to have reached higher levels of education than older people (CSO, 2007). Rural people are, as would be expected, less educated than their urban counterparts. On average, literacy was $91 \%$ for women and $95 \%$ for men [representing reading ability as defined by the ZDHS]. The two major urban centres of Harare and Bulawayo stood at $98 \%$ literacy. Four percent of males and $2 \%$ of females had more than a secondary education. Although literacy rates for males and females are almost similar, males slightly outnumber females among those who had never been to school.

The high levels of literacy have significant impacts as reflected through newspaper readership which stood at $40 \%$ for men and $25 \%$ for women (ZIMSTAT, 2013). Again urban residents had greater exposure to mass media than rural; $38 \%$ of households had access to a radio; $36 \%$ to a TV and $4 \%$ to a non-mobile phone. Media exposure is related to both education and wealth status. Africa Report (Africa in 2012, 2012) estimated 60\% mobile phone penetration. By 2014, the penetration rate had risen to 104\% (POTRAZ, 2014). About $37 \%$ of households had access to electricity connected via power lines [ $83 \%$ in urban areas and $13 \%$ rural districts] (ZIMSTAT, 2012).

Rising levels of literacy among Zimbabweans, especially women, greatly influence opportunities for employment as well as women fertility and the role of women in decision making at the individual and household levels. ZDHS reflected some of these shifts which represent significant changes that impact on retailers of all kinds. The proportion of women in employment stood at $43 \%$; while $57 \%$ had not worked in the 12 months preceding the survey (ZIMSTAT, 2012). Women and men with more than a secondary education were likely to be employed mostly in professional, technical and managerial jobs. On the other hand, urban women were most often employed in sales and services.

Marriage is nearly universal in Zimbabwe (ZIMSTAT, 2012) in different marriage types including polygynous unions. The age at marriage for women has risen from 18.7 to 19.9 over the last five years; it rises to 23.4 for those with a secondary education. With higher education, women postpone marriage and this impacts on family size and ultimately on population growth rates.

Notable changes were reported in levels of control married women had over their own earnings and hence on their ability to make independent buying decisions or to make joint decisions with their spouses/partners. This is a significant issue for retailers as Kotler and Keller (2006) highlighted. The survey (ZIMSTAT, 2012) reported that almost $1 / 3$ of employed women themselves mainly made decisions on using their own earnings; $62 \%$ decided jointly with their husbands and only $7 \%$ had this done mainly by their husbands. Women aged 35-49 were more likely to make such independent decisions. A surprising finding was that "there is little difference in control over women's cash earnings by urban-rural residence" (ZIMSTAT, 2012). Pointedly, only $2 \%$ of women with more than secondary education reported that their husbands mainly made decisions about how their wives' cash earnings were spent. These changes in women's roles have enormous implications for retailer. Obviously the rising numbers of single/unmarried women have complete independence in the disposal of their own incomes. 
With rising levels of education and increasing participation in employment, $14 \%$ of employed married women earned more than their husbands; $60 \%$ earned less than their husbands. Some $83 \%$ of husbands in the 15-49 age group said they made joint decisions with their wives and only $10 \%$ made independent decisions. Additionally, $13 \%$ of wives were the main decision makers even on their husbands' earnings; 73\% made joint decisions. Some 9\% of women owned a house alone and also 9\% for land (ZIMSTAT, 2012). The survey further established that $19 \%$ of women said they mainly made decisions about major household purchases such as furniture and home appliances, and equipment. Clearly women constitute a buying group to reckon with for all retailers of products and services.

As explained earlier, income is represented in the form of a wealth index in ZIMSTAT's demographic surveys. CSO (2010) showed that, as might be expected, $60 \%$ of the population in urban areas were in the highest wealth quintile compared to just over $1 \%$ for rural areas and households. Bulawayo, Zimbabwe's second largest city (Population: 653000 in 2012) had a higher proportion in the top quintile than Harare (Population: 2.1 million in 2012).

\section{CONCLUSIONS}

From the census and other demographic data, the principal features of the demographic profile of retail consumers were as follows:

- With a sex ratio of 94 men to a hundred women, females constitute $52 \%$ of the populations.

- The role and status of women as breadwinners, wage earners and employees continues to increase. More women have a growing voice is the disposal of their own earnings as well as the combined household incomes.

- With rising levels of literacy as well as employment opportunities for women, birth-rates have registered a decline and consequently the rate of population growth has slowed down aided by a higher level of outward migration to neighbouring countries especially in the hyperinflationary years up to 2009.

- Urban population growth is growing faster than the national average due to rural-urban migration. This is related to the growing presence and visible of retail chains in major towns and cities.

\section{RECOMMENDATIONS}

The following recommendations can be made retail practitioners:

- In crafting retail strategies and retail mixes, retailers need to consider the needs of a more literate and more educated group of consumers as Levy \& Weitz (2008) highlighted. With literacy levels at 97\%, (ZIMSTAT, 2013) no major changes can be expected on this statistic. However, the proportion of individuals with secondary education or higher can be expected to grow in future.

- Retailers must constantly review their markets as demographic factors are in a state of frequent change especially at the local level.

- It is necessary to undertake consumer behaviour surveys to understand the changing consumer dynamics especially in specific localities. In this vein, additional summary sheets and other data from ZIMSTAT provides valuable local data. An example is the ZIMSTAT (2014) series which gives demographic highlights by district.

- More households are headed by women especially in urban areas; some are child-headed. Retailers should therefore seek ways of developing knowledge of their special needs. 


\section{REFERENCES.}

1. Africa in 2012. (2012).

2. Anand, R. (2011). A study of determinants impacting consumers food choice with reference to the fast food consumption in India. Society and Business Review, 6(2), 176-187. http://doi.org/10.1108/17465681111143993

3. Berman, B., \& Evans, J. (2011). Retail Management: a strategic approach (11th ed.). Pearson.

4. Collins. (2008). Collins Concise English Dictionary (7th ed.). HarperCollins.

5. CSO. (1985). 1982 Population Census: Main demographic features of the population of Zimbabwe. Harare.

6. CSO. (2004). Census 2002. National Report. Harare.

7. CSO. (2007). Zimbabwe demographic and Health Survey 2005-06 [ZDHS]. Harare.

8. CSO. (2010). Multiple Indicator Monitoring Survey [MIMS]. Preliminary Report. Harare.

9. Easterby-Smith, M., Thorpe, R. and Jackson, P. R. (2008). Management Research. (3rd ed.). Sage.

10. Freathy, P. (2003). The Retailing Book: principles and applications. Prentice Hall.

11. Lee, H.-J., Cho, H. J., Xu, W., \& Fairhurst, A. (2010). The influence of consumer traits and demographics on intention to use retail self-service checkouts. Marketing Intelligence \& Planning, 28(1), 46-58. http://doi.org/10.1108/02634501011014606

12. Martínez, E., \& Montaner, T. (2008). Characterisation of Spanish store brand consumers. International Journal of Retail \& Distribution Management, 36(6), 477-493. http://doi.org/10.1108/09590550810873947

13. POTRAZ. (2014). POTRAZ Post. Harare.

14. Prasad, C. J., \& Aryasri, A. R. (2011). Effect of shopper attributes on retail format choice behaviour for food and grocery retailing in India. International Journal of Retail \& Distribution Management. http://doi.org/10.1108/09590551111104486

15. Saunders, A., Lewis, S., Thornhill, P. (2012). Research Methods for Business Students (6th ed.). London: Pearson Education.

16. Vanhonacker, F., Lengard, V., Hersleth, M., \& Verbeke, W. (2010). Profiling European traditional food consumers. British Food Journal. http://doi.org/10.1108/00070701011067479

17. Yin, R. (2009). Case study research:design and methods. (4th ed.). London: Sage.

18. ZIMSTAT. (2012). Zimbabwe Demographic and Health Survey. 2010-11. Harare.

19. ZIMSTAT. (2013). Census 2012. National Report. Harare.

20. ZIMSTAT. (2014). Zimbabwe in Maps. A Census Atlas. Harare. 